\title{
CARACTERIZAÇÃO DE AMBIENTES COM ALTA OCORRÊNCIA NATURAL DE ARATICUM (Annona crassiflora Mart.) NO ESTADO DE GOIÁS ${ }^{1}$
}

\author{
MARCOS ANTÔNIO MACHADO MESQUITA ${ }^{2}$, RONALDO VELOSO NAVES $^{3}$, ELI REGINABARBOZADE SOUZA $^{4}$, \\ TATIELY GOMES BERNARDES ${ }^{5}$, LUCIANABORGES E SILVA $^{6}$
}

RESUMO - Foram selecionadas 14 áreas no Estado de Goiás, Brasil, com alta densidade da espécie araticum (Annona crassiflora Mart.) e com menor ação antrópica possível. Cada área possuía 1,0ha, estando subdividida em quatro quadrantes $(0,25$ ha). Foram levantados os dados relativos às características físicas das áreas, das plantas e dos solos $(0-20 \mathrm{~cm})$. Os resultados demonstraram que o araticum tende a ocorrer em maior densidade em Latossolos não concrecionários dos chapadões, em formação de cerrado típico. A área basal total das plantas entre as áreas em estudo é influenciada positivamente pela concentração de Ca, Mg e $\mathrm{K}$ no solo. A densidade de plantas de araticum é influenciada negativamente pela concentração de Fe no solo. A distância geográfica entre as áreas não influenciou na densidade de plantas, na área basal média e na área basal total das plantas de araticum.

Termos para indexação: frutífera, cerrado, caracterização ambiental.

\section{ENVIRONMENTAL CHARACTERIZATION WITH HIGH NATURAL OCCURRENCE OF ARATICUM (Annona crassiflora Mart.) IN GOIÁS STATE}

\begin{abstract}
State of Goiás, Brazil, with high occurrence of the araticum specie (Annona crassiflora Mart.) and with smaller human being action possible. Each area had 1ha, and these areas were subdivided in four quadrants of $0,25 \mathrm{ha}$. The relative data of the areas, plants and soils physical characteristics $(0-20 \mathrm{~cm})$ was collected. The results demonstrated that the araticum tends to happen in larger density in "latossolos" in "concrecionários" of the plains in formation of typical cerrado. The total basal area of the araticum plants among the areas in study is influenced positively by the concentration of $\mathrm{Ca}, \mathrm{Mg}$ and $\mathrm{K}$ in the soil. The density of araticum plants is influenced negatively by the concentration of iron in the soil. The geographical distance among the areas did not influence the density of plants, in the medium and total basal area of the araticum plants.
\end{abstract}

Index terms: fruitful, cerrado, environmental characterization.

\section{INTRODUÇÃO}

Nos últimos 30 anos, observou-se rápida e crescente expansão da fronteira agrícola brasileira para a região dos Cerrados. Esse movimento tem ocorrido em resposta a vários fatores, podendo-se destacar: o aumento da demanda de produtos agrícolas, o deslocamento da capital federal para o Planalto Central, a proximidade dessa região com os principais centros consumidores e o seu enorme potencial agropecuário, tornando-se, assim, de importância para o desenvolvimento do Brasil (Goedert, 1989).

Apesar da homogeneidade fisionômica da vegetação do Cerrado, levantamentos já realizados mostram a riqueza em número de espécies e a grande variação na composição florística. Dentre essas espécies, muitas são fornecedoras de frutos comestíveis; porém sua utilização ainda é incipiente devido à falta de conhecimentos (Eiten, 1972). Destas, destaca-se o araticum por produzir frutos grandes, em torno de 1,0 kg (Naves et al., 1995), atrativos, com cheiro e sabor característicos, sendo muito apreciado pela fauna e pela população local, tornando-os valorizados para comercialização. Porém, a oferta de frutos de araticum vem reduzindo-se devido à enorme pressão antrópica sobre o bioma cerrado, aliado às dificuldades naturais de produção das anonáceas (São José, 1997). Esses fatos justificam a necessidade de mais estudos sobre as espécies do cerrado e, em especial, sobre as frutíferas, de forma a minimizar os efeitos da ação do homem sobre o cerrado, contribuindo para a preservação destas espécies e criando condições para sua incorporação ao processo produtivo. Para isso, no entanto, torna-se necessário conhecer melhor o ambiente onde essas espécies ocorrem naturalmente.

Este trabalho teve como objetivo caracterizar, nas condições do Cerrado do Estado de Goiás, ambientes de alta ocorrência natural do araticum (Annnona crassiflora Mart.) através de variáveis edafoclimáticas.

'(Trabalho 091-2005). Recebido em 03-06-2005. Aceito para publicação em 05-12-2006.

${ }^{2}$ Eng. Agr. MSc. (Parte da dissertação de Mestrado). EA/UFG. Goiânia-GO. marcosmesquita2004@bol.com.br

${ }^{3}$ Doutor em Agronomia. Professor Adjunto da Escola de Agronomia e Engenharia de Alimentos (EA) da Universidade Federal de Goiás (UFG). Cx. Postal 131 - 74001-970 Goiânia- GO.ronaldo@agro.ufg.br

${ }^{4}$ Eng $^{a}$ Agr ${ }^{a}$. Doutoranda em Agronomia. EA/UFG. Goiânia- GO. eliregina.souza@ pop.com.br

${ }^{5}$ Eng $^{\mathrm{a}}$ Agra $^{\text {a }}$ Mestranda em Agronomia. EA/UFG. Goiânia- GO. tatielygb@bol.com.br

${ }^{6}$ Eng $^{\mathrm{a}}$ Agr ${ }^{\mathrm{a}}$. Doutoranda em Agronomia. EA/UFG. Goiânia- GO. 1borges1001@yahoo.com.br 


\section{MATERIAL E MÉTODOS}

Como base de informações iniciais, por levantamento realizado por Naves (1999), selecionaram-se, no Estado de Goiás, de abril de 2000 a maio de 2001, 14 áreas para o desenvolvimento dos trabalhos (Tabela 1).

As seguintes condições foram adotadas como critérios para a escolha de cada área: maior densidade de plantas de araticum, ou seja, com mais de 17 plantas/ha (Naves, 1999), menor ação antrópica, ser característica de cerrado, possuir pelo menos 10ha, ser a mais uniforme possível quanto à fisionomia do cerrado e ao tipo de solo.

Para o estudo de caracterização do ambiente, em cada área estudada, foi delimitada uma área de amostragem, de formato quadrado, contendo um hectare, o qual foi dividido em quatro parcelas iguais ou quadrantes (0,25ha/quadrante).

Os parâmetros vegetais observados foram: densidade de plantas de araticum (DP), área basal média (ABM) e área basal total $(\mathrm{ABT})$, do tronco a $10 \mathrm{~cm}$ do solo. Foram consideradas as plantas de araticunzeiros com o diâmetro igual ou superior a $3,18 \mathrm{~cm}$.

Os parâmetros do solo analisados foram: fósforo (P), cálcio $(\mathrm{Ca}), \mathrm{Mg}$ (magnésio), potássio (K), alumínio (Al), $\mathrm{pH}$, cobre $(\mathrm{Cu})$, ferro $(\mathrm{Fe})$, manganês $(\mathrm{Mn})$, zinco $(\mathrm{Zn})$ e argila, a uma profundidade de $0-20 \mathrm{~cm}$, onde ocorre maior variação química dos solos de cerrado (Adámoli, 1985; Naves, 1999).

Foram calculadas as temperaturas médias mensais normais do ar, utilizando-se da latitude e altitude das áreas e dos dados levantados nas Estações Climatológicas da Rede INEMET - Instituto Nacional de Meteorologia (MARA, 1992), mais próximas às áreas e corrigidas de acordo com o método sugerido por Tubelis \& Nascimento (1981).

Realizou-se a análise de variância, sendo consideradas as 14 áreas como tratamentos e cada quadrante como repetição, utilizando-se do delineamento inteiramente casualizado. Procedeu-se ao estudo das correlações de Pearson (Steel \& Torrie, 1960) entre as médias dos parâmetros do solo e entre as médias dos parâmetros do solo com os parâmetros vegetais.

A partir dos parâmetros dos solos e dos vegetais, obtiveram-se uma matriz de distâncias dos solos e uma matriz de distâncias das plantas, utilizando-se como medida da Distância Generalizada de Mahalanobis (Mahalanobis, 1936), resultante de uma análise multivariada para variáveis quantitativas, implementada pelo Programa Genes (Cruz, 1997).

$\mathrm{Na}$ análise de regressão múltipla, foi realizado o estudo de correlação entre as médias dos parâmetros vegetais, a latitude e a altitude das áreas estudadas. Foi realizada a análise de correlação canônica para os parâmetros vegetais e de solo, conforme Cruz e Regazzi (1994).

\section{RESULTADOS E DISCUSSÃO}

Nas quatorze áreas amostradas no Estado de Goiás, foi encontrado um total de 884 plantas de araticum consideradas adultas, com diâmetro igual ou superior a $3,18 \mathrm{~cm}$ a $10 \mathrm{~cm}$ do solo, perfazendo uma média de 63,14 plantas por hectare. Resultado esse superior ao encontrado por Naves (1999), que foi de 23,14 plantas de araticum por hectare, embora se deva considerar que este trabalho priorizou áreas com maior ocorrência natural de araticum.

O diâmetro médio observado para as plantas foi de $13,90 \mathrm{~cm}$, variando de $3,18 \mathrm{~cm}$ a $49,36 \mathrm{~cm}$, apresentando mediana de $12,42 \mathrm{~cm}$. Cerca de $54 \%$ das plantas encontravam-se no intervalo de $5 \mathrm{~cm}$ a $15 \mathrm{~cm}$ de diâmetro.

A área basal total variou de um mínimo de $0,394 \mathrm{~m}^{2} / a ́ r e a$ em Serranópolis, até um máximo de 3,047m²/área em Água Fria, com média de $1,23 \mathrm{~m}^{2} / \mathrm{ha}$.

Observando-se os dados obtidos para altitude (Tabela 1), com exceção dos municípios de Itarumã (570m), na região sudeste, e de Vila Propício (680m), na região nordeste do Estado, as outras áreas estavam acima de $810 \mathrm{~m}$ até $1.280 \mathrm{~m}$. Isto reafirma o que foi observado por Naves (1999), que o araticum, no bioma cerrado, tende a ocupar áreas mais altas, localizadas nos chapadões, tornando essa espécie mais vulnerável, pois, nestes locais, a pressão antrópica voltada, principalmente, para a realização de culturas anuais, tem reduzido sensivelmente as áreas de vegetação nativa do cerrado.

As áreas em estudo possuem pouca declividade (Tabela 1), sendo esta condição esperada, por ser, a maioria, constituída por Latossolos, visto que essa classe de solo tende a ocorrer em ambientes menos movimentados (Haridasan, 1993).

A temperatura média calculada foi de $21,3{ }^{\circ} \mathrm{C}$, com uma variação de $19,9^{\circ} \mathrm{Ca} 22,6^{\circ} \mathrm{C}$. Obteve-se pequena diferença térmica entre as áreas em estudo, mesmo tendo áreas com menor altitude, pois, neste caso, essa foi compensada pelo efeito da latitude (Tabela 1).

Verifica-se que houve predominância dos Latossolos (71,4\% das áreas) principalmente da cor Vermelha ou Vermelhoamarela. Este resultado era esperado, considerando que os Latossolos ocupam próximo a 50\% das áreas dos cerrados, sendo esta a classe de solos dominante neste ambiente e por estarem associados à vegetação de cerrado típico e a um relevo mais suave, normalmente com declividade de até 8\% (Haridasan, 1993). As outras quatro áreas foram classificadas como Neossolos quartzarenos, estando localizadas em menores altitudes. Não foram encontrados locais com alta concentração natural de plantas de araticum em outras classes de solos que também ocorrem no cerrado, como os Cambissolos, Litossolos e mesmo em Latossolos Concrecionários ou associados a solos com alta saturação de água permanente ou temporária.

Em função do tipo de vegetação, 12 áreas foram classificadas como cerrado típico; uma no município de Água Fria como cerradão, e uma em Alto Paraíso como cerrado aberto, estabelecendo-se a preferência do araticum pela fitofisionomia característica do bioma cerrado.

O pequi (Caryocar brasiliense Camb.) ocorreu em $71 \%$ das áreas e o pau-terra-de-folha-larga (Qualea grandiflora Mart.) em $64 \%$ destas, sendo estas consideradas plantas arbóreas companheiras do araticum. 
TABELA 1 - Características das áreas estudadas, de ocorrência natural de araticum (Annona crassiflora Mart.) no Estado de Goiás. UFG, 2000.

\begin{tabular}{|c|c|c|c|c|c|c|}
\hline \multirow[b]{2}{*}{$\begin{array}{c}\text { Área } \\
N^{\circ} .\end{array}$} & \multirow[b]{2}{*}{ Município } & \multirow[b]{2}{*}{$\begin{array}{l}\text { Altitude } \\
\text { (m) }\end{array}$} & \multicolumn{4}{|c|}{ Coordenada geográfica } \\
\hline & & & $\begin{array}{l}\text { Temperatura } \\
\text { média }\left({ }^{\circ} \mathrm{C}\right)\end{array}$ & Latitude Sul & $\begin{array}{c}\text { Longitude } \\
\text { Oeste }\end{array}$ & $\begin{array}{c}\text { Declividade } \\
(\%)\end{array}$ \\
\hline 1 & Orizona & 940 & 20,9 & $16^{\circ} 56^{\prime} 54^{\prime \prime}$ & $48^{\circ} 23^{\prime} 44^{\prime \prime}$ & 1 \\
\hline 2 & Orizona & 950 & 20,8 & $16^{\circ} 48^{\prime} 10^{\prime \prime}$ & $48^{\circ} 12^{\prime} 05^{\prime \prime}$ & 3 \\
\hline 3 & Cristalina & 900 & 21,0 & $17^{\circ} 00^{\prime} 54^{\prime \prime}$ & $47^{\circ} 19^{\prime} 02^{\prime \prime}$ & 5 \\
\hline 4 & Rio Verde & 1000 & 20,5 & $17^{\circ} 19^{\prime} 25^{\prime \prime}$ & $51^{\circ} 33^{\prime} 47^{\prime \prime}$ & 4 \\
\hline 5 & Serranópolis & 820 & 21,2 & $17^{\circ} 52^{\prime} 47^{\prime \prime}$ & $52^{\circ} 29^{\prime} 48^{\prime \prime}$ & 5 \\
\hline 6 & Chapadão do Céu & 840 & 21,0 & $18^{\circ} 20^{\prime} 13^{\prime \prime}$ & $52^{\circ} 49^{\prime} 58^{\prime \prime}$ & 0 \\
\hline 7 & Itarumã & 570 & 22,3 & $18^{\circ} 43^{\prime} 31^{\prime \prime}$ & $51^{\circ} 24^{\prime} 21^{\prime \prime}$ & 5 \\
\hline 8 & Guapo & 880 & 21,2 & $16^{\circ} 51^{\prime} 30^{\prime \prime}$ & $49^{\circ} 28^{\prime} 10^{\prime \prime}$ & 1 \\
\hline 9 & Vila Propício & 680 & 22,6 & $15^{\circ} 12^{\prime} 25^{\prime \prime}$ & $48^{\circ} 43^{\prime} 51^{\prime \prime}$ & 2 \\
\hline 10 & Água Fria & 870 & 21,7 & $14^{\circ} 59^{\prime} 26^{\prime \prime}$ & $47^{\circ} 46^{\prime} 30^{\prime \prime}$ & 3 \\
\hline 11 & Alto Paraíso & 1280 & 19,9 & $14^{\circ} 07^{\prime} 47^{\prime \prime}$ & $47^{\circ} 32^{\prime} 21^{\prime \prime}$ & 4 \\
\hline 12 & Campos Belos & 810 & 22,5 & $13^{\circ} 00^{\prime} 48^{\prime \prime}$ & $46^{\circ} 25^{\prime} 15^{\prime \prime}$ & 2 \\
\hline 13 & Posse & 820 & 22,2 & $14^{\circ} 06^{\prime} 54^{\prime \prime}$ & $46^{\circ} 21^{\prime} 00^{\prime \prime}$ & 3 \\
\hline 14 & Cabeceiras & 1030 & 20,7 & $15^{\circ} 36^{\prime} 12^{\prime \prime}$ & $47^{\circ} 06^{\prime} 44^{\prime \prime}$ & 3 \\
\hline
\end{tabular}

TABELA 2 -Matriz de correlações entre médias de áreas (acima da diagonal) e entre médias dos quadrantes (abaixo da diagonal) considerando os parâmetros analisados do solo $(0 \mathrm{a} 20 \mathrm{~cm})$ e os parâmetros vegetais do araticum (Annona crassiflora Mart.), das 14 áreas avaliadas no Estado de Goiás. UFG, 2000.

\begin{tabular}{|c|c|c|c|c|c|c|c|c|c|c|c|c|c|c|c|c|c|c|c|}
\hline & $\mathrm{P}$ & $\mathrm{Ca}$ & $\mathrm{Mg}$ & K & $\mathrm{Al}$ & $\mathrm{pH}$ & $\mathrm{MO}^{1}$ & CTC.T. $^{2}$ & CTC.E. ${ }^{3}$ & V & S.Al & $\mathrm{Cu}$ & $\mathrm{Fe}$ & $\mathrm{Mn}$ & $\mathrm{Zn}$ & Arg. & $\mathrm{DPA}^{4}$ & $\mathrm{ABM}^{5}$ & $\mathrm{ABT}^{6}$ \\
\hline$P$ & 1 & -0.3392 & -0.3472 & -0.4320 & -0.3511 & 0.2773 & -0.5027 & -0.5121 & -0.4288 & 0.0199 & 0.1665 & 0.0291 & -0.0117 & -0.3123 & -0.4206 & -0.3939 & 0.3103 & $-0,2889$ & $-0,0588$ \\
\hline $\mathrm{Ca}$ & 0.2746 & 1 & $0.7022^{* *}$ & 0.4776 & 0.3076 & 0.0572 & -0.0406 & 0.1149 & 0.5236 & $0.6358^{*}$ & -0.2256 & -0.0538 & -0.4034 & 0.2174 & 0.2964 & -0.0853 & -0.2902 & $0,8656^{* *}$ & $0,6960^{* *}$ \\
\hline Mg & 0.2847 & $0.6621^{* *}$ & 1 & $0.8093^{* *}$ & 0.0048 & 0.2690 & 0.4684 & 0.4420 & 0.2624 & 0.2973 & $-0.5581^{*}$ & 0.4701 & -0.2240 & $0.5492^{*}$ & $0.5761^{*}$ & 0.4320 & 0.1579 & $0,5320^{*}$ & $0,7415^{* *}$ \\
\hline K & 0.1010 & $0.5721^{* *}$ & $0.4919^{* *}$ & 1 & 0.3156 & 0.1967 & $0.7038^{* *}$ & $0.6994 * *$ & 0.5039 & -0.0166 & -0.2560 & $0.5813^{*}$ & -0.0450 & $0.6733^{* *}$ & $0.5759^{*}$ & $0.6642^{* *}$ & 0.0828 & 0,4352 & $0,5779^{*}$ \\
\hline $\mathrm{Al}$ & -0.0580 & -0.0463 & 0.0058 & 0.0213 & 1 & -0.3263 & 0.2186 & 0.5126 & $0.9630^{* *}$ & -0.1931 & $0.7272^{* *}$ & -0.1480 & 0.0335 & 0.0067 & 0.0981 & 0.0726 & -0.3170 & 0,1836 & $-0,0443$ \\
\hline $\mathrm{pH}$ & -0.1563 & 0.2262 & 0.0778 & 0.1711 & -0.0761 & 1 & -0.2079 & -0.3314 & -0.2430 & 0.2575 & -0.3694 & 0.3758 & -0.2488 & 0.1378 & 0.0353 & -0.2196 & 0.1019 & $-0,0289$ & 0,1212 \\
\hline MO & $0.3439 *$ & 0.2996 & $0.4805^{* *}$ & 0.2589 & 0.0327 & -0.0736 & 1 & $0.9300^{* *}$ & 0.2867 & $-0.6028^{*}$ & -0.1240 & 0.4652 & 0.2069 & 0.3978 & $0.5879^{*}$ & $0.9560^{* *}$ & 0.3432 & $-0,1019$ & 0,2117 \\
\hline CTC.T. & -0.0742 & -0.1068 & 0.1991 & -0.0873 & 0.1472 & 0.0125 & 0.2055 & 1 & $0.5692^{*}$ & $-0.5992^{*}$ & 0.1273 & 0.2848 & 0.1022 & 0.3114 & 0.5130 & $0.8569^{* *}$ & 0.2276 & $-0,0042$ & 0,2417 \\
\hline CTC.E. & 0.0565 & $0.3251^{*}$ & $0.3378^{*}$ & $0.3082^{*}$ & $0.9193^{* *}$ & 0.0065 & 0.1880 & 0.1323 & 1 & -0.0526 & $0.5448^{*}$ & -0.0519 & -0.0537 & 0.1406 & 0.2288 & 0.1434 & -0.3049 & 0,3742 & 0,1759 \\
\hline $\mathrm{V}$ & 0.2767 & $0.5499 * *$ & $0.3175^{*}$ & $0.3332^{*}$ & 0.0227 & -0.0124 & 0.1627 & $-0.5521^{* *}$ & 0.2187 & 1 & -0.3892 & -0.0926 & -0.2692 & 0.1819 & -0.0377 & $-0.5763^{*}$ & -0.4321 & $0,7077^{* *}$ & 0,3323 \\
\hline S.Al & -0.2356 & $-0.4989 * *$ & $-0.4596 * *$ & $-0.3110^{*}$ & $0.4731^{* *}$ & -0.0641 & $-0.3266^{*}$ & 0.0822 & 0.2345 & $-0.6248^{* *}$ & 1 & -0.3109 & 0.2166 & -0.3300 & -0.3904 & -0.2024 & -0.0912 & $-0,2860$ & $-0,4152$ \\
\hline $\mathrm{Cu}$ & -0.1372 & 0.0800 & 0.0308 & -0.0837 & 0.0603 & -0.1267 & -0.1079 & 0.0468 & 0.0703 & 0.1151 & -0.0844 & 1 & 0.2795 & $0.6809^{* *}$ & $0.5861^{*}$ & 0.4004 & 0.4446 & $-0,1305$ & 0,2276 \\
\hline $\mathrm{Fe}$ & -0.1218 & 0.1984 & 0.0944 & $0.3464^{*}$ & -0.0048 & 0.0995 & -0.0986 & -0.0251 & 0.0850 & 0.0894 & -0.0438 & 0.1905 & 1 & 0.1486 & 0.1444 & 0.1859 & -0.1626 & $-0,4335$ & $-0,5664^{*}$ \\
\hline $\mathrm{Mn}$ & 0.2615 & $0.4698^{* *}$ & $0.4812^{* *}$ & $0.3272 *$ & 0.1570 & -0.0713 & $0.3948^{* *}$ & 0.1348 & $0.3475^{*}$ & 0.1651 & -0.1756 & $0.3222^{*}$ & 0.1044 & 1 & 0.5307 & 0.3908 & 0.0125 & 0,2354 & 0,2683 \\
\hline $\mathrm{Zn}$ & $0.3395^{*}$ & 0.1188 & 0.2432 & 0.1318 & $0.3066^{*}$ & -0.2402 & 0.2053 & -0.0318 & $0.3568^{*}$ & $0.3750^{*}$ & $-0.3074^{*}$ & 0.0565 & 0.0543 & 0.2163 & 1 & 0.4764 & -0.0252 & 0,1161 & 0,1884 \\
\hline Arg. & -0.1233 & -0.1079 & -0.1766 & -0.1876 & 0.2595 & -0.1026 & -0.1354 & -0.1761 & 0.1746 & -0.1657 & $0.4615^{* *}$ & -0.0317 & -0.0621 & -0.0009 & $-0.3885^{*}$ & 1 & 0.3615 & $-0,0537$ & 0,2785 \\
\hline DPA & -0.0369 & -0.1056 & -0.2212 & -0.0287 & 0.0780 & -0.2045 & 0.0793 & 0.0709 & 0.0152 & -0.0541 & 0.0539 & -0.2656 & $-0.4287^{* *}$ & -0.2663 & 0.0038 & -0.1234 & 1 & $-0,3644$ & 0,3437 \\
\hline ABM & 0,0787 & 0,1858 & $-0,0494$ & 0,1867 & $-0,1494$ & 0,0728 & 0,1261 & $-0,1764$ & $-0,0867$ & 0,0444 & $-0,0867$ & 0,2330 & $0,4075^{* *}$ & 0,2624 & $-0,0058$ & 0,1197 & $-0,3407^{*}$ & 1 & 0,7096 \\
\hline ABT & 0,1382 & $-0,0606$ & $-0,2686$ & 0,1272 & $-0,0028$ & $-0,2503$ & 0,1164 & $-0,1707$ & $-0,0418$ & $-0,0591$ & 0,0980 & $-0,3729 *$ & $-0,1420$ & $-0,1507$ & $-0,1266$ & 0,1225 & $0,6660^{* *}$ & 0,0607 & 1 \\
\hline
\end{tabular}

${ }^{1}$ MO = Matéria Orgânica ${ }^{2}$ CTC.T. $=$ Capacidade de Troca Catiônica Total ${ }^{3}$ CTC.E. $=$ Capacidade de Troca Catiônica Efetiva ${ }^{4}$ DPA = Densidade de Plantas de Araticum ${ }^{5} \mathrm{ABM}=$ Área Basal Média ${ }^{6} \mathrm{ABT}=$ Área Basal Total

TABELA 3 - Parâmetros vegetais e dos solos com elevada ocorrência do araticunzeiro (Annona crassiflora Mart.) em 14 áreas no Estado de Goiás. UFG, 2000.

\begin{tabular}{|c|c|c|c|c|c|c|c|c|c|c|c|c|c|c|c|c|c|c|c|}
\hline & $\mathrm{P}$ & $\mathrm{Ca}$ & $\mathrm{Mg}$ & $\mathrm{K}$ & $\mathrm{Al}$ & \multirow{2}{*}{$\begin{array}{r}\mathrm{pH} \mathrm{em} \\
\left(\mathrm{H}_{2} \mathrm{O}\right)\end{array}$} & \multirow{2}{*}{$\begin{array}{c}\mathrm{MO} \\
\left(\mathrm{g} \cdot \mathrm{dm}^{-3}\right)\end{array}$} & СТC T. & CTC E. & \multirow{2}{*}{\multicolumn{2}{|c|}{$\begin{array}{l}\mathrm{V} \\
(\%)\end{array}$}} & $\mathrm{Cu}$ & $\mathrm{Fe}$ & $\mathrm{Mn}$ & \multirow[t]{2}{*}{$\mathrm{Zn}$} & \multirow{2}{*}{$\begin{array}{l}\text { Argila } \\
\left(\mathrm{g} \mathrm{dm}^{-3}\right)\end{array}$} & \multirow{2}{*}{$\begin{array}{l}\mathrm{N}^{\circ} \mathrm{de} \\
\text { plantas }\end{array}$} & $\mathrm{ABM}$ & $\mathrm{ABT}$ \\
\hline & $\left(\mathrm{mg} \cdot \mathrm{dm}^{-3}\right)$ & & $(\mathrm{cmo}$ & $\left.\mathrm{dm}^{-3}\right)$ & & & & (cmo & $\left.\mathrm{dm}^{-3}\right)$ & & & & (mg & $\left.\mathrm{n}^{-3}\right)$ & & & & & \\
\hline 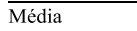 & 1,01 & 0,18 & 0,11 & 0,08 & & 5,09 & 28,00 & 6,65 & 1,58 & 5,95 & 75,23 & & 83,16 & 8,75 & & 412,00 & 16,00 & 0,02 & 0,31 \\
\hline Valor & & 0,5 & & 0, & & & 46,0 & 10,2 & & 10,9 & & 3,4 & 0 & 27, & & & 37 , & 0,0 & 0,94 \\
\hline & & & & & & & & & & & & & & & & & & & 0,03 \\
\hline C.V. (\%) & 51,59 & 41,01 & 41,15 & 49,92 & 37,27 & 9,11 & 52,17 & 31,89 & 32,19 & 34,18 & 12,27 & 55,32 & 26,74 & 83,83 & 31,59 & 53,05 & 45,96 & 73,46 & 61,14 \\
\hline
\end{tabular}


Na caracterização química (Tabela 3) dos solos das áreas de cerrado com alta ocorrência natural de araticum, verifica-se que, de acordo com a Comissão de Fertilidade de Solos de Goiás (1988), praticamente todos os solos foram classificados como de nível baixo a muito baixo para os principais nutrientes: $\mathrm{P}, \mathrm{Ca}, \mathrm{Mg}$ e K, bem como o Zn. Por outro lado, o Al apresenta-se em nível médio a alto, e o pH foi classificado de fortemente ácido a ácido. A matéria orgânica apresentou teores de baixo a médio, estando em condição quase inativa, em vista da pobreza dos solos (Pereira $\&$ Peres, 1985).

Os teores de argila apresentaram um intervalo de variação de $80 \mathrm{~g} \cdot \mathrm{kg}^{-1}$ a $730 \mathrm{~g} \cdot \mathrm{kg}^{-1}$ (Tabela 3), com média de $412 \mathrm{~g} \cdot \mathrm{kg}^{-}$ ${ }^{1}$ e mediana de $460 \mathrm{~g} \cdot \mathrm{kg}^{-1}$. Mais de $71 \%$ dos solos das áreas em estudo mostraram mais de $150 \mathrm{~g} . \mathrm{kg}^{-1}$ de argila, considerados de textura média a argilosa (Vieira et al., 1988). Contudo, esses valores não representam maior CTC, pois, nos minerais presentes nestes solos, existe o predomínio da caulinita como tipo de argila, sendo esta, predominantemente, constituída de óxidos de ferro e de alumínio (Embrapa, 1978).

Os valores obtidos para os teores de nutrientes do solo das áreas em estudo (Tabela 3 ) foram considerados baixos a muito baixos, porém estão próximos aos encontrados em outros levantamentos realizados no ambiente natural do cerrado, principalmente para o cerrado típico, onde está a grande maioria das áreas em estudo (Lopes, 1983; Naves et al. 1995; Tomé Júnior, 1997; Naves, 1999). O araticum, no entanto, por ser planta nativa de solos com o predomínio de baixa oferta nutricional, embora seja responsiva a $\mathrm{Ca}, \mathrm{Mg}$ e $\mathrm{K}$ em termos de área basal (Tabela 2), consegue conviver e produzir, em alguns casos, elevada quantidade de frutos. Acredita-se no potencial desta espécie, pois uma vez superadas questões relativas à polinização e à pressão de insetos-praga (São José, 1997), a elevada adaptação a ambientes de baixa oferta nutricional credencia esta espécie como possuidora de características muito oportunas de serem estudadas e avaliadas no ambiente cerrado.

Para todos os parâmetros de solo avaliados, houve diferenças significativas entre áreas, pelo teste de "F", ao nível de $1 \%$ de probabilidade. Esse comportamento já era esperado, pois os nutrientes, os elementos tóxicos e a argila tendem a ocorrer no solo de forma variada e diferenciada, como ficou evidenciado neste trabalho, concordando com estudos efetuados por Naves (1999) sobre solos de cerrado.

Na Tabela 2, os valores encontrados acima da diagonal referem-se à matriz de correlações entre médias de áreas. Observa-se que, em $10 \%$ dos casos, os parâmetros analisados do solo se correlacionaram ao nível de $1 \%$ de probabilidade. Os macronutrientes $\mathrm{Ke} \mathrm{Mg}$ e os micronutrientes $\mathrm{Mn}$ e $\mathrm{Cu}$ estabeleceram os maiores índices de correlações significativas. O Fe e o Zn não apresentaram correlações significativas e mostraram baixa variação nas áreas. No entanto, o P, a saturação em $\mathrm{Al}$ e em bases, e os micronutrientes $\mathrm{Cu}$ e Fe estabeleceram correlações negativas com os demais parâmetros do solo.

A matriz de correlações residuais é apresentada na Tabela 2, abaixo da diagonal. Essas correlações medem a variação conjunta dos parâmetros analisados ao nível de quadrantes dentro de áreas, correspondendo, portanto, à microvariação dos parâmetros de solo. O número de correlações entre os parâmetros foi ligeiramente maior em relação às correlações entre as médias das áreas. O sentido das correlações estabelecidas (se negativo ou positivo) tendeu a aumentar nas correlações residuais.

Dentro das áreas, ocorreu maior número de correlações com o cálcio, o magnésio e a saturação de Al. Verificou-se que o $\mathrm{P}$, o pH, o $\mathrm{Cu}$, o $\mathrm{Fe}$ e o $\mathrm{Zn}$ não apresentaram correlação ao nível de $1 \%$ de significância (Tabela 2).

$\mathrm{O} \mathrm{Mn}$ correlacionou-se positivamente com o $\mathrm{Cu}$ e o $\mathrm{K}$ entre as áreas, ao nível de $1 \%$ de significância e dentro das áreas estabeleceu-se ao nível de 5\% (Tabela 2).

Entre as áreas, houve forte influência positiva dos teores de $\mathrm{Ca}, \mathrm{Mg}$ e $\mathrm{K}$ sobre a área basal média e a área basal total das plantas de araticum. Em especial, o $\mathrm{Ca}$, que se correlacionou significativamente ao nível de $1 \%$ com estes dois parâmetros. A densidade de plantas manteve-se indiferente a esses parâmetros de solo (Tabela 2). Esse comportamento mostra que, embora as plantas de araticum sejam adaptadas aos solos pobres do cerrado, elas respondem favoravelmente em termos de crescimento em diâmetro do tronco na presença de maiores teores de $\mathrm{Ca}, \mathrm{Mg}$ e $\mathrm{K}$.

$\mathrm{O} F$ e dentro das áreas mostrou comportamento contrário à densidade de plantas e positivo em relação à área basal. Entre as áreas, embora não-significativo, houve uma tendência negativa em relação aos parâmetros vegetais analisados (Tabela 2). Esse micronutriente necessita ser melhor estudado em relação às plantas de araticum.

As correlações das matrizes de distâncias geográficas, dos parâmetros vegetais e de solos não foram significativas, indicando que a variação entre tipos de solos e entre vegetais não está estruturada geograficamente.

As duas maiores distâncias dos vegetais e dos solos foram observadas entre as áreas 1 e 10 e entre as áreas 3 e 7, que estão separadas entre si, respectivamente, a distâncias de $250 \mathrm{~km}$ e $493 \mathrm{~km}$. Outras áreas, entretanto, mesmo separadas entre si a distâncias geográficas acima desse valor, apresentaram menores distâncias de vegetais e solos.

As correlações obtidas não alcançaram o nível de significância; contudo, os coeficientes das correlações apresentadas entre a altitude e a ABM, e a latitude e a DPA mostraram-se relevantes, merecendo estudos mais detalhados. A correlação entre a altitude e a ABM foi negativa, apresentando uma tendência de se encontrarem plantas com menor diâmetro em áreas com maiores altitudes. Obteve-se correlação negativa entre a latitude e a DPA, indicando tendência de se encontrar, em maiores latitudes, menor densidade de plantas.

As correlações obtidas para os três pares canônicos (vegetais, solos e geográficos) não foram significativas. Para os pares canônicos, a ABM apresentou o maior coeficiente canônico, representando, assim, a maior dissimilaridade dentre os parâmetro vegetais. Em relação aos parâmetros de solo, os maiores coeficientes foram obtidos para Ca positivamente e para $\mathrm{Mg}$ negativamente. 


\section{CONCLUSÕES}

Para as áreas estudadas, conclui-se:

1- $\mathrm{O}$ araticum ocorre em maior densidade em cerrado típico, localizado nos Latossolos não- concrecionários dos chapadões. 2- $\mathrm{O}$ araticum convive em ambiente com baixo nível de oferta nutricional.

3- A área basal total das plantas de araticum é influenciada positivamente pelos níveis de $\mathrm{Ca}, \mathrm{Mg}$ e $\mathrm{K}$ no solo.

4- A densidade de plantas de araticum é influenciada negativamente pelo nível de ferro no solo.

5- A distância geográfica entre as áreas não influenciaram na densidade de plantas, na área basal média e na área basal total das plantas de araticum.

\section{REFERÊNCIAS}

ADÁMOLI, J.; MACEDO, J.; AZEREDO, L. G.; MADEIRANETO, J. Caracterização da região dos cerrados. In: GOEDERT, W. J. (Ed.). Solos dos cerrados: tecnologias e estratégias de manejo. São Paulo: Nobel, Brasília: EMBRAPA/CPAC, 1985. p.33-74.

COMISSÃO DE FERTILIDADE DE SOLO DE GOIÁS. Recomendações de corretivos e fertilizantes para Goiás: $5^{\text {a }}$ aproximação. Goiânia: UFG/EMGOPA, 1988. 101p.

CRUZ, C. D. Programa GENES: Aplicativo computacional em genética e estatística. Viçosa: Editora UFV, 1997. 442p.

CRUZ, C. D.; REGAZZI, A. J. Modelos biométricos aplicados ao melhoramento genético. Viçosa: Editora UFV, 1994.390p.

EITEN, G. The cerrado vegetation of Brazil. The Botanical Review, New York, v.38, n.2, p.201-341, 1972.

EMBRAPA. Serviço nacional de levantamento e conservação de solos. Levantamento de reconhecimento dos solos do Distrito Federal. Rio de Janeiro: EMBRAPA/SNLCS, 1978. 455p. (Boletim Técnico, 53).

GOEDERT, W. J. Região dos cerrados: potencial agrícola e política para seu desenvolvimento. Pesquisa Agropecuária Brasileira, Brasília, v.24, n.1, p.1-17, 1989.

HARIDASAN, M. Solos do Distrito Federal. In: PINTO, M.N. (Org.) Cerrado: caracterização, ocupação e perspectivas. 2. ed. Brasília: UnB, 1993, p.321-344.

LOPES, A. S. Solos sob "Cerrado": características, propriedades e manejo. 2.ed. Piracicaba: Associação Brasileira para Pesquisa da Potassa e do Fosfato, 1983. 162p.

MAHALANOBIS, P. C. On the generalized distance in statistics. Proceedings of the National Institute Science, New Delhi, v. 2, p. 49-55, 1936.

MARA. Ministério da Agricultura e Reforma Agrária. Normais climatológicas (1961-1990). Brasília: Secretaria Nacional de Irrigação. Departamento Nacional de Meteorologia, 1992.

NAVES, R. V. Espécies frutíferas nativas dos cerrados de Goiás: caracterização e influências do clima e do solo. 1999. $206 \mathrm{f}$. Tese (Doutorado em Produção Vegetal)- Escola de Agronomia e Engenharia de Alimentos, Universidade Federal de Goiás, Goiânia, 1999.
NAVES, R. V.; ALMEIDANETO, J. X.; ROCHA, M. R.; BORGES, J. D.; CARVALHO, G. C.; CHAVES, L. J.; SILVA, V. A. Determinação de características físicas em frutos e teor de nutrientes, em folha e no solo, de três espécies frutíferas de ocorrência natural nos cerrados de Goiás. Anais das Escolas de Agronomia e Veterinária, Goiânia, v.25, n.2, p.107-114, 1995.

PEREIRA, J.; PERES, J. R. R. Manejo da matéria orgânica. In: GOEDERT, W.J. Solos dos cerrados: tecnologia e estratégia de manejo. São Paulo: Nobel, Brasília: EMBRAPA/CPAC, 1985. p.261-284.

SÃO JOSÉ, A. R. Aspectos gerais das anonáceas no Brasil. In: SÃO JOSÉ, A. R.; SOUZA, I. V. B.; MORAIS, O. M.; REBOUÇAS, T. N. H. (Ed.). Anonáceas: produção e mercado. Vitória da Conquista: Universidade Estadual do Sudoeste da Bahia, 1997. p.5-6.

STEEL, R. G. D.; TORRIE, J. H. Principles and procedures of statistics with special reference to the biological sciences. New York: Mcgraw-Hill Book Company, 1960. 479p.

TOMÉ JUNIOR, J. B. Manual para interpretação de análise de solo. Guaíba: Agropecuária, 1997. 247p.

TUBELIS, A.; NASCIMENTO, F. J. L. Meteorologia descritiva. São Paulo: Nobel, 1981. 174p.

VIEIRA, L. S.; SANTOS, P. C. T.; VIEIRA, M. N. F. Solos: Propriedades, classificação e manejo. Brasília: MEC/ABEAS, 1988. 154p. 